\title{
Mechanical properties and nanostructures in a duplex stainless steel subjected to equal channel angular pressing
}

\author{
L. Chen, F.P. Yuan, P. Jiang, X.L. Wu* \\ State Key Laboratory of Nonlinear Mechanics, Institute of Mechanics, Chinese Academy of Science, Beijing 100190, PR China
}

\section{A R T I C L E I N F O}

\section{Article history:}

Received 28 March 2012

Accepted 30 April 2012

Available online 9 May 2012

\section{Keywords:}

Nanostructure

Equal channel angular pressing

Mechanical property

Duplex stainless steel

\begin{abstract}
A B S T R A C T
The nanostructure and resultant mechanical property were studied in an UNS S32304 duplex stainless steel subjected to equal channel angular pressing. The successive refinement of original grains was observed to happen in dual phases, i.e., austenite and ferrite, during 4-pass pressing. Both phases exhibit similar lamellar features of microstructures by the formation of dislocation boundaries and their misorientation evolution with increasing strains. The deformation twinning and martensitic transformation as well were observed to happen in austenite. The transversal spacing of elongated grains is $79 \mathrm{~nm}$ in austenite and $130 \mathrm{~nm}$ in ferrite, respectively. After annealing at $973 \mathrm{~K}$ for $20 \mathrm{~min}$, the elongated grains tend to become equiaxed, and the average size of nanograins increases to $108 \mathrm{~nm}$ in austenite and $235 \mathrm{~nm}$ in ferrite, respectively. The tensile tests show that the yield strength of the dual-phase nanostructure is $1460 \mathrm{MPa}$ after 4-pass pressing, as compared to $403 \mathrm{MPa}$ of its coarse-grained counterpart, but with uniform elongation of merely $2 \%$. After annealing at $973 \mathrm{~K}$, the uniform elongation increases to $7 \%$ with the yield strength of $1100 \mathrm{MPa}$. In addition, different stages of strain hardening were observed in various microstructures during tensile testing, and the corresponding plastic responses were discussed.
\end{abstract}

(C) 2012 Elsevier B.V. All rights reserved.

\section{Introduction}

Strength and ductility are two key mechanical properties for structural materials [1,2]. Nanostructured metallic materials produced by severe plastic deformation techniques usually have high strength but relatively low tensile ductility, which is mainly attributed to their low strain hardening ability [3-5]. Several strategies based on microstructural designing have been developed recently aiming at improvement of poor ductility of nanostructured metals, including the introduction of a bimodal grain size distribution [6], the preexisting nanoscale growth twins [1], dispersions of nano-precipitates [7,8], transformation- and twinning-induced plasticity $[9,10]$, and a mixture of two or multiple phases with varying size scales and properties [11].

The dual-phase nanostructures have attracted extensive interest recently for their potential ability to enhance the mechanical properties of nanostructured materials [11]. The different mechanical properties between component phases would result in additional interaction stresses and strains during deformation [12]. So the strain hardening ability of dual-phase nanostructure is closely related to the different plastic responses of separate phases. In the case of dual-phase steels, for example, consisting of martensite and ferrite both with a body center cubic (bcc) structure, the

\footnotetext{
* Corresponding author. Tel.: +86 108254 3957; fax: +8610 62561284 .

E-mail address: xlwu@imech.ac.cn (X.L. Wu).
}

ultrafine-grained ferrite together with isolated martensite islands could be generated by equal channel angular pressing (ECAP). The ultrafine-grained microstructures have high strain hardening rate during tensile deformation, due to the generations of mobile dislocations of high density in ferrite [13-15].

There is another kind of dual-phase material named as duplex stainless steel (DSS), consisting of bcc ferrite and face center cubic (fcc) austenite. The austenite has the yield strength a little higher than that of ferrite $[16,17]$, mainly due to solid solution strengthening of nitrogen atom in austenite. The mechanical responses of separate phase to applied strain are different from each other, as evidenced by in situ neutron [18] and X-ray diffraction methods [17]. Meanwhile, the distribution of plastic strains is heterogeneous between two phases and the ferrite will accommodate greater plastic strain than austenite during tensile testing [12,19]. Besides, the strain hardening rate in austenite is observed to be greater than that in ferrite during plastic deformation [20]. Accordingly, the austenite possesses a high strength at first, and this difference in strength between austenite and ferrite would be enlarged with increasing of the applied strain. Previous studies on DSS subjected to rolling/swaging deformation exhibit that the deformation twinning in austenite should lead to more rapid grain subdivision than that in ferrite at the early stage of deformation, but further deformation would result in the development of similar (sub)grain sizes in both phases [20]. However, the influence of the resultant microstructure on the mechanical behaviors of nanostructured DSS has not been studied in sufficient details. 
In present paper, a dual-phase nanostructure was prepared in the UNS S32304 DSS by ECAP. The mechanical properties and corresponding nanostructures were investigated. Special attentions were paid to the microstructure evolution during ECAP and the influence of resultant microstructure on the strain hardening behavior during tensile deformation.

\section{Experimental procedures}

The DSS used in this investigation is UNS S32304, with chemical composition (wt.\%) of $0.02 \mathrm{C}, 0.5 \mathrm{Si}, 1.2 \mathrm{Mn}, 23.5 \mathrm{Cr}, 4.0 \mathrm{Ni}, 0.4 \mathrm{Mo}$, $0.13 \mathrm{~N}, 0.024 \mathrm{P}, 0.002 \mathrm{~S}$, and balanced Fe. The initial billets of diameter $10 \mathrm{~mm}$ were annealed at $1373 \mathrm{~K}$ for $2 \mathrm{~h}$, followed by oil quenching in vacuum of about $10^{-4} \mathrm{~Pa}$.

The ECAP processing was conducted using a split die with two channels intersecting at inner angle of $90^{\circ}$ and outer angle of $30^{\circ}$, yielding an effective strain about 1 by each pass. The samples using for tensile tests were pressed for 4 passes ( $4 \mathrm{P}$ ) at room temperature by route $B_{c}[21,22]$.

The deformed billets were then cut into dog-bone shape tensile specimen by electrical discharging along extrusion direction on $Y$ planes. The $Y$ plane is parallel to the side faces while $X$ plane is perpendicular to the extrusion direction $[21,23,24]$.

The samples for tensile testing have a rectangular cross-section of $2 \mathrm{~mm} \times 1 \mathrm{~mm}$ and a gauge length of $8 \mathrm{~mm}$. All tensile tests were carried out using an Instron 8871 test machine with uniaxial quasistatic strain rate of $2 \times 10^{-4} \mathrm{~s}^{-1}$ at room temperature. At least three times of tensile testing were conducted for each microstructure.

The phase constitutions of various microstructures were identified by X-ray diffraction (XRD) analysis on the $Y$ planes using Rigaku $\mathrm{D} / \mathrm{max} 2400 \mathrm{X}$-ray diffractometer with $\mathrm{Cu} \mathrm{K} \alpha$ radiation, and a step size of $0.02^{\circ}$.

Two methods were used to measure the content of austenite. One is to measure the area fraction based on the contrast in gray scale of optical micrographs [25], while the other is to calculate the intensity ratio based on X-ray diffraction (XRD). The factor $F$ is defined to indicate the variation of relative amount of austenite [26], i.e.

$F=\frac{I_{f c c(111)}}{I_{f c c(111)}+I_{b c c(110)}}$,

where $I_{\mathrm{fcc}(111)}$ and $I_{\mathrm{bcc}(110)}$ are the diffraction intensities of fcc (1 111$)$ and bcc (1 110$)$ peaks, respectively.

The microstructural evolution during the ECAP process was investigated using Olympus PMG3 optical microscope (OM) and Hitachi 800 transmission electron microscope (TEM). The chemical etchant used for OM observation was a solution of $30 \mathrm{~g} \mathrm{~K}_{3} \mathrm{Fe}(\mathrm{CN})_{6}$, $10 \mathrm{~g} \mathrm{KOH}$ and $100 \mathrm{ml} \mathrm{H}_{2} \mathrm{O}$. The etchant solution was first water bathed at $353 \mathrm{~K}$, and then the sample was immersed into the solution for $3 \mathrm{~min}$. Thin foils of about $0.5 \mathrm{~mm}$ thick for TEM observation were first cut by electrical discharging on $X$ and/or $Y$ planes, and then ground to the thickness of about $50 \mu \mathrm{m}$, and finally polished by twin-jet polishing with a solution of 95\% ethyl alcohol and 5\% perchloric acid $\left(\mathrm{HClO}_{4}\right)$ at $253 \mathrm{~K}$.

\section{Results}

\subsection{Mechanical property}

Fig. 1(a) shows the tensile engineering stress-strain curves of different microstructures. It is seen that the yield stress is $1460 \mathrm{MPa}$ after 4-pass pressing, about 3.6 times higher than $403 \mathrm{MPa}$ of the as-annealed microstructure. However, the uniform elongation decreases significantly from $25.4 \%$ to $2 \%$. After annealing at $973 \mathrm{~K}$ for $20 \mathrm{~min}$, the uniform elongation and elongation to failure increase to $7 \%$ and $17.5 \%$, respectively, though the yield stress and ultimate tensile strength decrease to $1100 \mathrm{MPa}$ and $1433 \mathrm{MPa}$. Fig. 1(b) displays the tensile mechanical properties of current DSS in comparison with several other metallic materials processed by severe plastic deformation techniques, including ferritic [27,28], austenitic [29] and dual phase (DP) steels [30-32]. It is visible that nanostructured DSS has higher strength than DP steels at the same level of ductility.

In order to clarify the physical nature of plastic responses of various microstructures during tensile deformation, modified Crusard-Jaoul (C-J) model based on the Swift equation [33] was selected to display different strain hardening stages. This model is considered to be sensitive to different strain hardening stages especially for dual-phase microstructures [34]. The Swift stress-strain relationship is expressed as

$\varepsilon=\varepsilon_{0}+k \sigma^{m}$,

where $\varepsilon$ and $\sigma$ are the true strain and true stress, respectively, $m$ is the strain hardening exponent, and $\varepsilon_{0}$ and $k$ are material constants. The differentiation of the logarithmic form of Eq. (2) with respect to $\varepsilon$ gives

$\ln \left(\frac{d \sigma}{d \varepsilon}\right)=(1-m) \ln \sigma-\ln (k m)$,

Then, $m$ values can be obtained from the slopes of the $\ln (d \sigma / d \varepsilon) v s$. $\ln \sigma$ curves.

Fig. 2 shows the $\ln (d \sigma / d \varepsilon)$ vs. $\ln \sigma$ curves of three kinds of microstructures. Two transitions are visible for the as-annealed microstructure, separating the whole tensile process into three stages (left curve). The corresponding $m$ values are 9.6, 9.8 and 3.5 for three hardening stages, with initial true strains of $0.2 \%, 0.4 \%$ and $1.5 \%$, respectively. In contrast, only one hardening stage happens
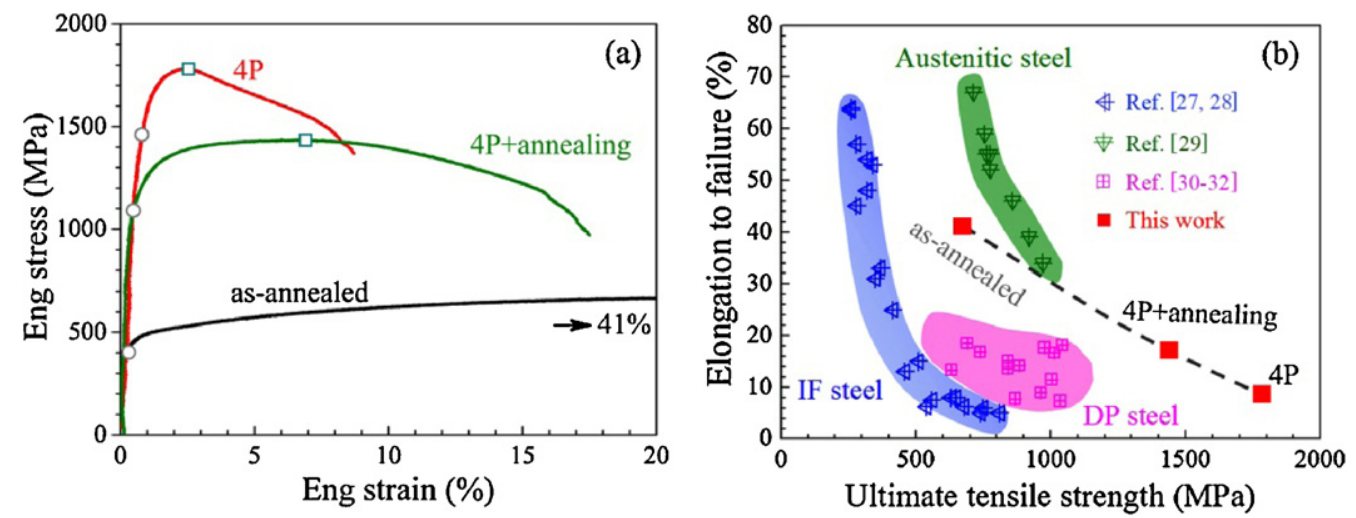

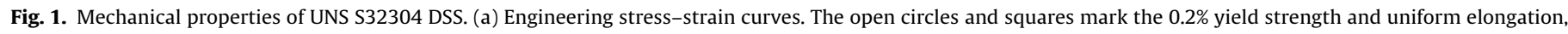
respectively. (b) Elongation to failure vs. ultimate tensile strength for different steels subjected to severe plastic deformation. 


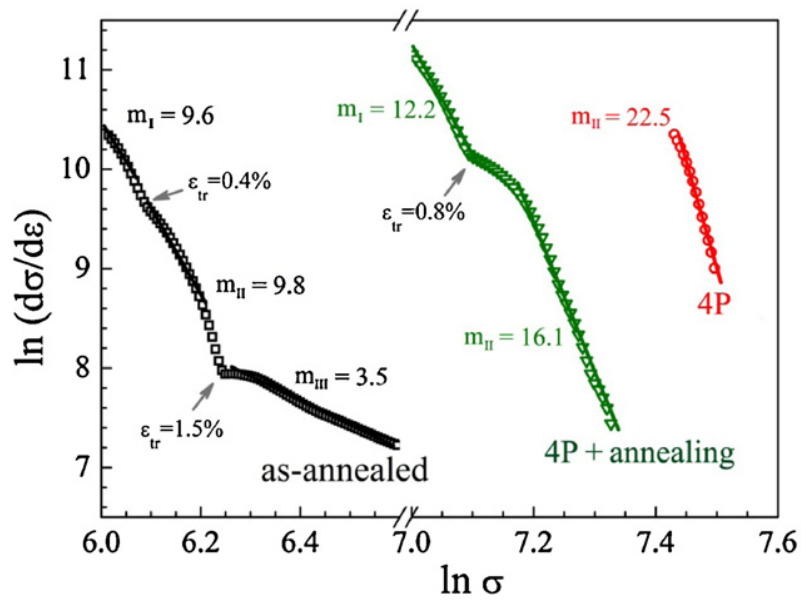

Fig. 2. Logarithmic strain hardening rate $v s$. the logarithmic true stress for various microstructures. Different strain hardening stages are visible. The values of $m$ and $\varepsilon$ are also marked.

in deformed microstructure (right curve), but with a much high $m$ value of 22.5. After annealing, however, the transition appears again (middle curve), with $m$ values of 12.1 and 16.1, and corresponding initial strains of $0.2 \%$ and $0.8 \%$, respectively. It should be mentioned that the transition usually implies the onset of new plastic response with applied strain, leading to an increase in the strain hardening ability [13]. In addition, the $m$ values may reflect the strain hardening ability qualitatively. The lower the $m$ value is, the larger the ability of strain hardening will be. Hence, after annealing, the ability of strain hardening gets evident recovery.

\subsection{Microstructure observation}

The optical micrograph of as-annealed microstructure is shown in Fig. 3. Both austenite $(\gamma)$ and ferrite $(\alpha)$ are clearly visible, with bright and dark contrast, respectively.

The phase constitutions of different microstructures were identified by XRD measurement. Fig. 4(a) is the XRD patterns of four kinds of microstructures. The as-annealed microstructure consists of $\alpha$ and $\gamma$. No precipitate was detected after 1-pass (1P), 4-pass pressing, and post-ECAP annealing as well. Fig. 4(b) gives the fractions of austenite in four kinds of microstructures measured via two methods, i.e., the area fraction and intensity ratio. The austenite accounts for about $45 \%$ in as-annealed microstructure by both $\mathrm{OM}$ and XRD measurement. During ECAP process, the fraction of austenite declines gradually, and decreases by about $5 \%$ after 4 -pass pressing. After annealing, however, the fraction of austenite almost rises to the initial level again. It indicates that phase transformation in austenite may happen during ECAP process and reversely

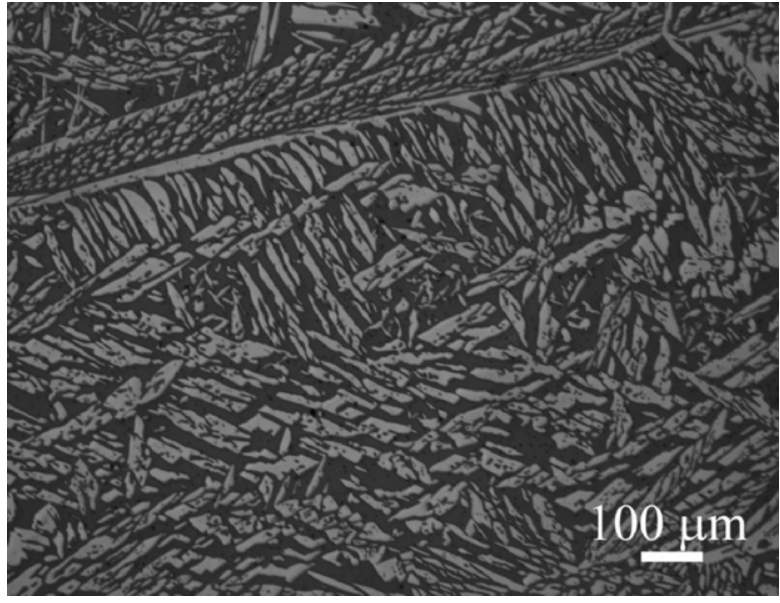

Fig. 3. Optical micrograph of the as-annealed microstructure. The bright area is austenite, while the dark one is ferrite.

transform to austenite during subsequent annealing. No $\varepsilon$ martensite was detected by XRD analysis in present study. It is consistent with previous studies about DSS subjected to plastic deformation and subsequent annealing, in which the $\gamma$ transformed directly to $\alpha^{\prime}$ and reverse transformed to $\gamma$ when annealing at $773 \mathrm{~K}$ [35].

The microstructure after 1-pass pressing is shown in Fig. 5. Fig. 5(a) is the bright-field TEM micrograph showing deformation twins in austenite. The inset is the selected area electron diffraction (SAED) pattern of twins. The intersection of deformation twins along two directions is visible. The deformation twins will induce grain refinement via subdivision of twin boundaries into submicrosized blocks [36]. The dislocation tangles are also visible near twin boundaries and inside the interiors. Fig. 5(b) exhibits the elongated subgrains consisting of low-angle dislocation boundaries in ferrite. The inset is the SAED pattern, indicating of low angle misorientations.

Fig. 6(a) exhibits the deformed microstructure after 4-pass pressing viewed from $Y$ plane. It is visible that the $\gamma$ is refined greatly by comparison of $\alpha$. Fig. 6(b) and (c) is TEM micrographs with high magnification, showing the morphologies of the ferrite and austenite, respectively. Both phases exhibit the lamellar features, consisting of elongated grains and subgrains. Based on two insets, it is seen that the misorientation angles increase as compared with those in Fig. 5. Fig. 6(d) shows the static distribution of lamellar spacing of both austenite and ferrite, with the average sizes of $79 \mathrm{~nm}$ and $130 \mathrm{~nm}$, respectively.

The deformation induced phase transformation was observed to occur in $\gamma$ after 4-pass pressing, as shown in Fig. 7. Fig. 7(a) shows nearly equiaxed nanostructure after 4-pass pressing when viewed
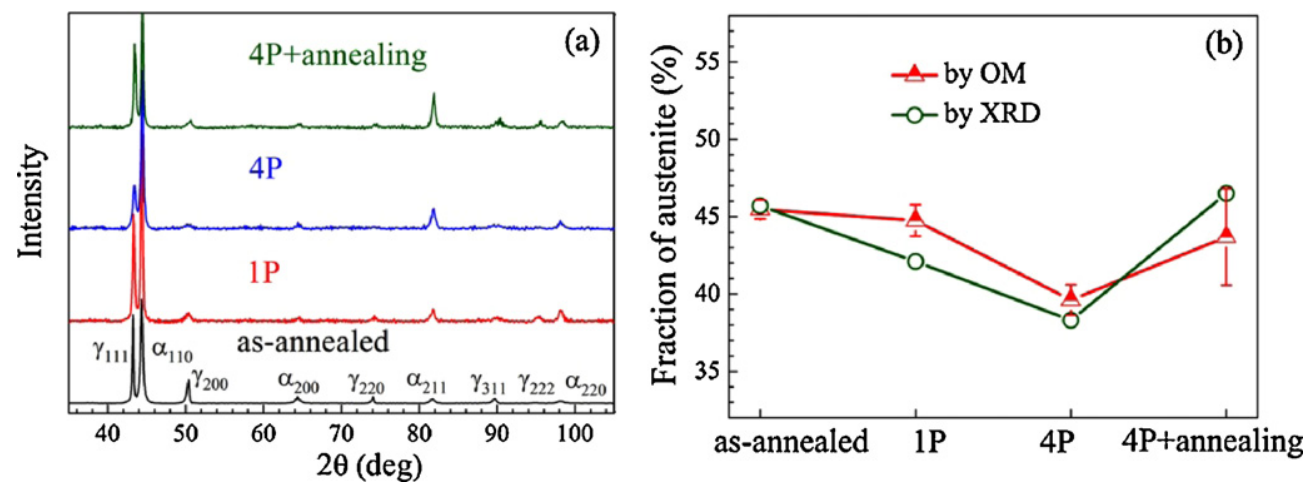

Fig. 4. (a) XRD patterns of various microstructures. (b) Corresponding area fractions and intensity ratios of austenite. 

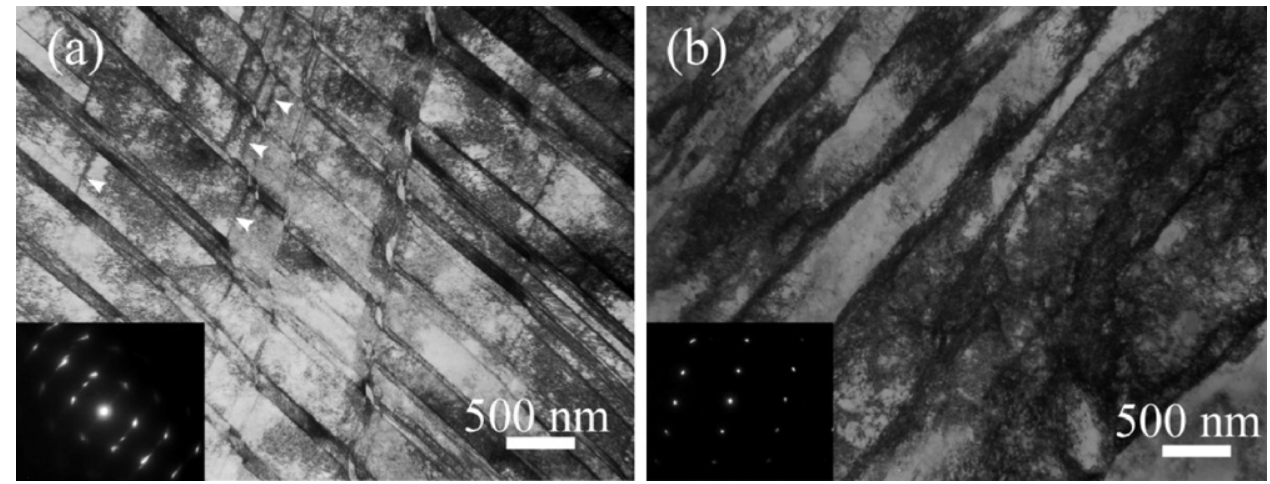

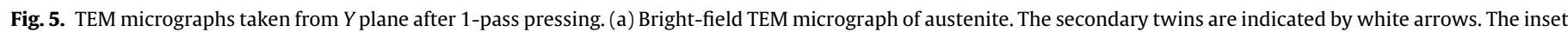

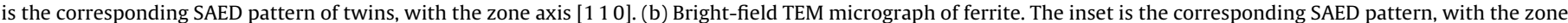
axis [ $\overline{1} 13]$.
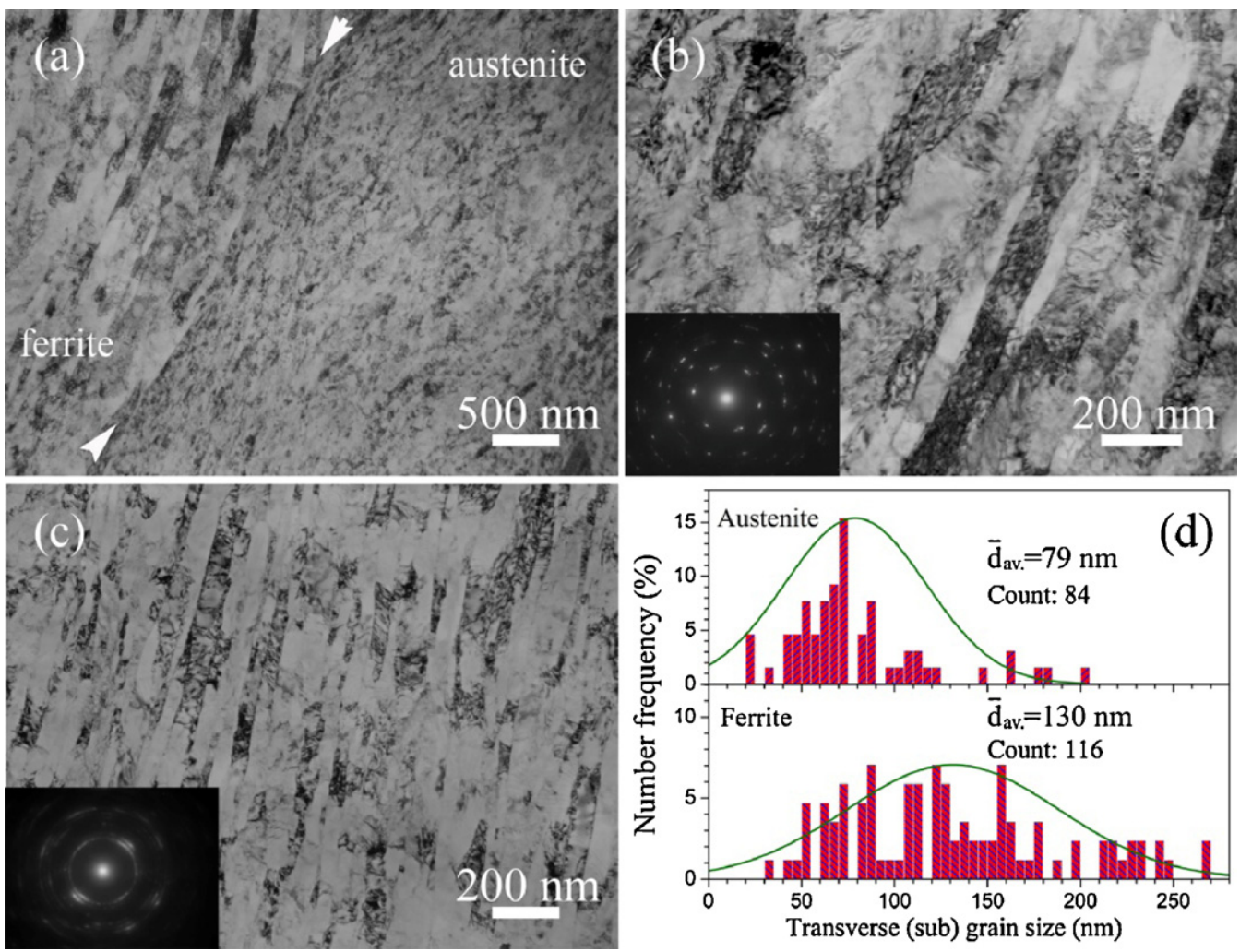

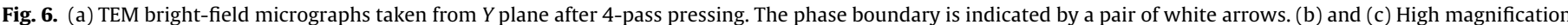

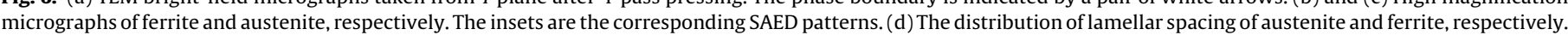

from $X$ plane. This is typical of the microstructure for many metals processed by ECAP for 4 passes when viewed from $X$ plane [21]. Fig. 7(b) is the dark-field TEM micrograph, indicating the formation of $\alpha^{\prime}$ martensite within austenite. Fig. 7(c) is the corresponding SAED pattern taken from the area covering austenite and $\alpha^{\prime}$ martensite. The diffraction rings indicate the crystal structure of austenite and $\alpha^{\prime}$ martensite respectively, as marked in Fig. 7(c).

After annealing at $973 \mathrm{~K}$ for $20 \mathrm{~min}$, the nanostructure is shown in Fig. 8(a). Fig. 8(b) and (c) is bright-field TEM micrographs of ferrite and austenite with high magnification. The grains in both phases appear almost equiaxed, with visible grain boundary fringes and low-density dislocations in their interiors. Fig. 8(d) is the distribution of grain sizes for both austenite and ferrite, with the average sizes of $108 \mathrm{~nm}$ and $235 \mathrm{~nm}$, respectively. It indicates that both phases have grain growth during annealing, but the grains in ferrite tend to grow larger than that in austenite.

\section{Discussion}

Heterogeneous microstructure was observed after 4-pass pressing, with the average grain size of $79 \mathrm{~nm}$ in austenite and $130 \mathrm{~nm}$ in ferrite, respectively, as shown in Fig. 6. The grain refinement mechanisms are different between austenite and ferrite during the ECAP process. At the early stage of ECAP, the ferrite should be refined by successive subdivision of dislocation walls due to the operation of multi-slip systems. Further deformation will increase the portion of high-angle grain boundaries owing to rotation of subgrains, leading to the formation of nanostructure in ferrite [37-40]. However, the deformation mechanisms of austenite are associated with dislocation slip and deformation twinning. The intersection of deformation twins may result in rapid subdivision of coarse grains into submicro-sized blocks, which could be further refined by the formation of micro twins and dislocation boundaries inside 

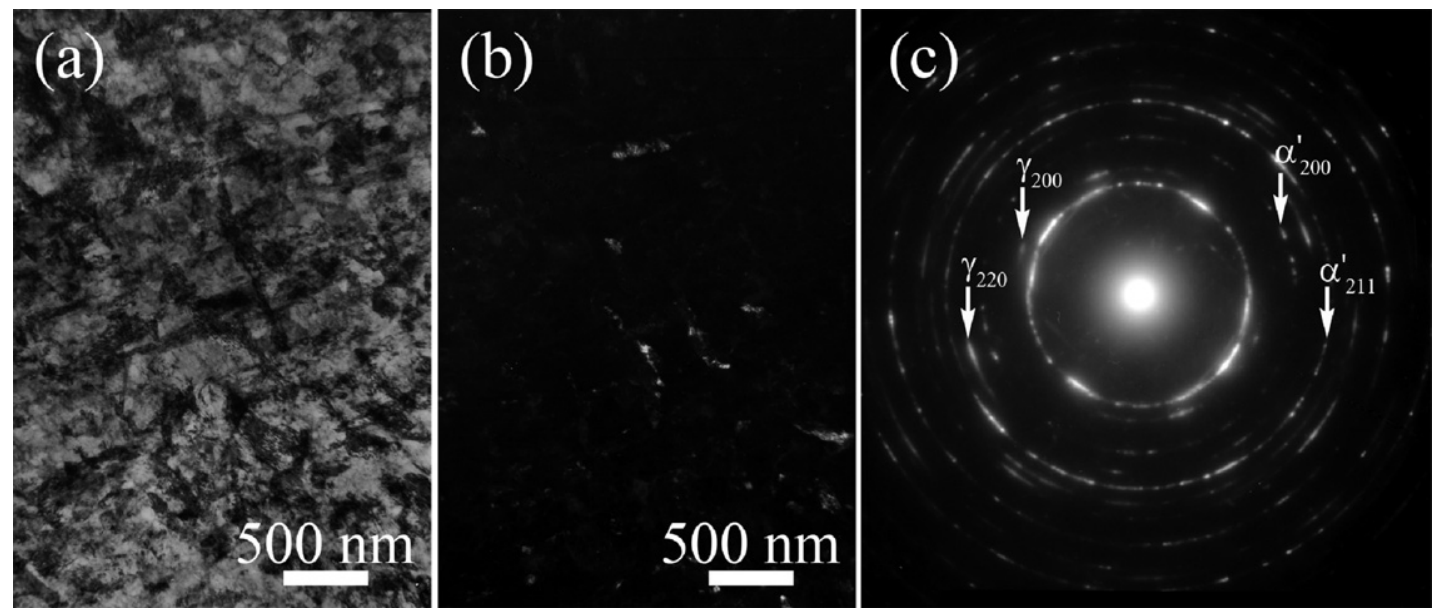

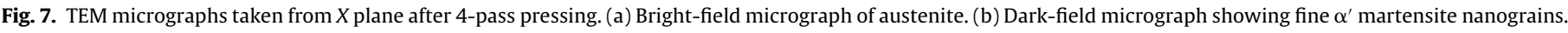
(c) The corresponding SAED pattern.

the interiors [36]. Fig. 5(a) shows the deformation twins along two directions and high-density dislocations near twin boundaries and inside the interiors, indicating that the austenite is refined simultaneously by twin-twin and twin-dislocation intersections [41]. Hence, the grain refinement mechanisms are different between austenite and ferrite in DSS, leading to heterogeneous microstructure after 4-pass pressing.

Various stages of strain hardening are observed in three kinds of microstructures, as shown in Fig. 2. The $\ln (d \sigma / d \varepsilon) v s . \ln (\sigma)$ curve of as-annealed microstructure consists of three stages, indicating various plastic responses during tensile testing. The first stage indicates that the ferrite is deformed plastically while the austenite only elastically. With increasing of strain, the onset of yielding in austenite lead to the presence of the second stage, similar to what happened in conventional dual-phase steels [13-15]. The third stage may arise as a result of deformation twinning in austenite, the same as that in austenitic steels during tensile testing [42]. There is just one stage for deformed microstructure, which may due to the formation of comparable strength between austenite and ferrite. After annealing at $973 \mathrm{~K}$ for $20 \mathrm{~min}$, however, a two-stage feature appears again. The true strain at transition for post-ECAP annealed microstructure $(0.8 \%)$ is close to the first transitional strain of as-annealed microstructure $(0.4 \%)$. Hence, the appearance of two-stage feature of post-ECAP annealed microstructure is mainly attributed to the reintroduction of difference in yield strength between austenite and ferrite, similar as prior two stages
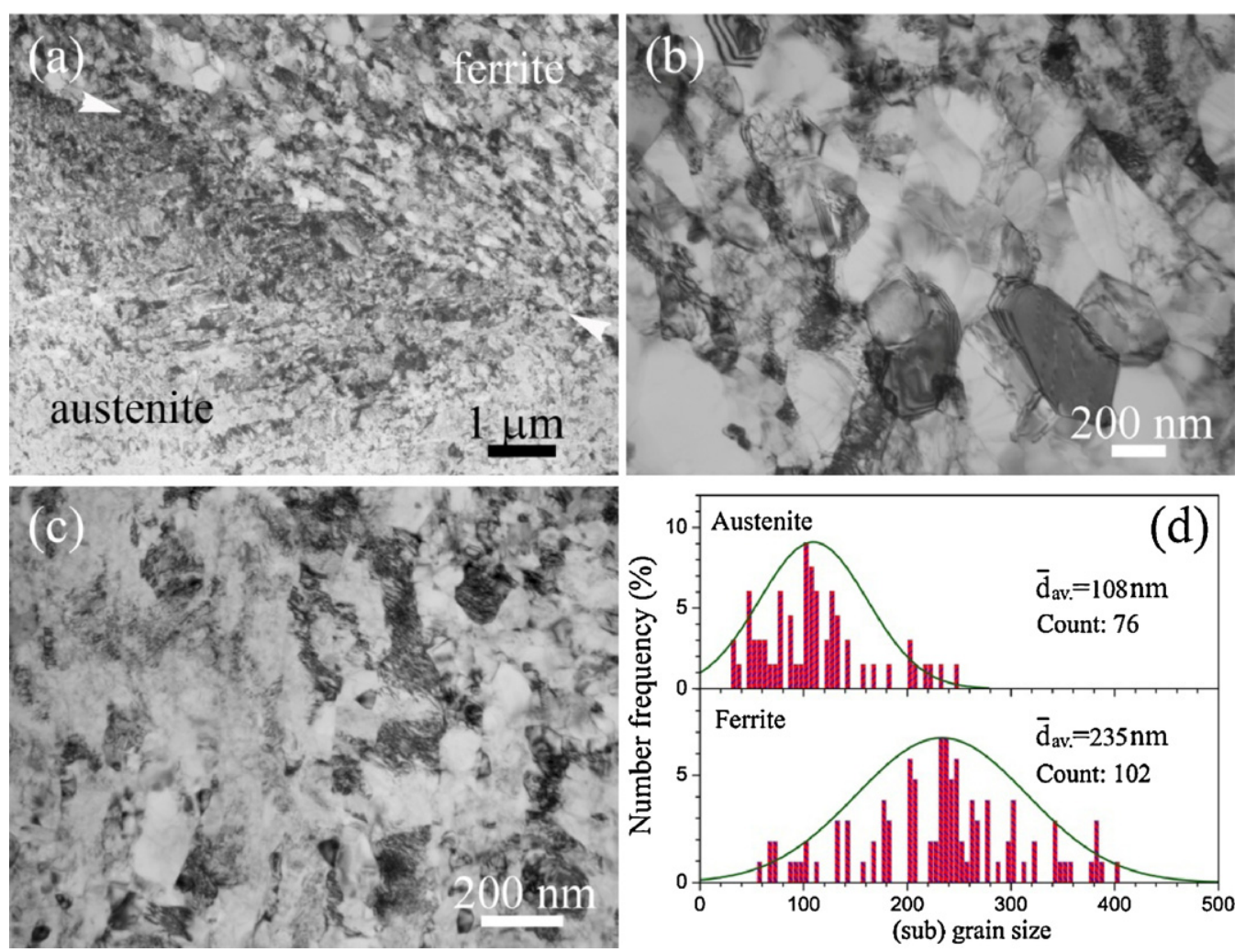

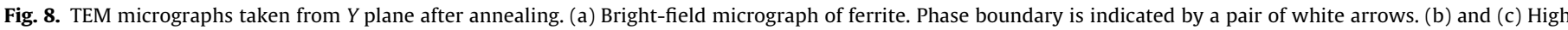
magnification micrographs of ferrite and austenite, respectively. (d) The distribution of (sub)grain sizes for austenite and ferrite, respectively. 
of as-annealed microstructure. Moreover, the second transition is presented in as-annealed state but absent in post-ECAP annealed condition, indicating that the deformation twinning is difficult to operate in nanostructure during tensile testing. It is consistent with the previous studies that deformation twinning is difficult in ultrafine grains under tensile deformation, in spite of prevalence in coarse-grained counterpart [43].

The ability of strain hardening is qualitatively reflected by $m$ values. For as-annealed microstructure, $m$ value in third stage $\left(m_{\mathrm{III}}=3.5\right)$ is observed to be less than that in prior two stages $\left(m_{\mathrm{I}}=9.6, m_{\mathrm{II}}=9.8\right)$, indicating improvement of strain hardening ability due to deformation twinning. The deformed microstructure exhibits one much high $m$ value, suggesting much low ability of strain hardening during tension. Hence, the uniform elongation is much low. After annealing, however, it is interesting to note evident decreasing in $m$ values and presence of two-stage feature of strain hardening. The relatively low $m$ values imply that the strain hardening ability could be recovered by annealing, owing to the generations and interactions of mobile dislocations, along with probable phase interactions during tensile deformation. Meanwhile, the $m$ value of post-ECAP annealed microstructure in second stage is evidently larger than that in first stage. It should be attributed to dynamic recovery of dislocations during tensile deformation, leading to decreasing of strain hardening ability $[13,15]$.

\section{Conclusions}

A dual-phase nanostructure consisting of $\alpha$ and $\gamma$ was generated by ECAP technique. The mechanical properties are investigated by uniaxial tensile testing and the microstructures are characterized by XRD, OM and TEM. Meanwhile, the strain hardening behaviors of various microstructures during tensile testing were discussed in detail. The main conclusions are summarized as follows.

1. Both austenite and ferrite exhibit similar lamellar features of microstructures after 4-pass pressing, with average spacing of $79 \mathrm{~nm}$ and $130 \mathrm{~nm}$, respectively. After annealing at $973 \mathrm{~K}$ for $20 \mathrm{~min}$, the grains tend to become equiaxed and grain growth takes place in both phases. The average (sub)grain sizes in postECAP annealed condition are $108 \mathrm{~nm}$ in austenite and $235 \mathrm{~nm}$ in ferrite, respectively.

2. The yield strength of the dual-phase nanostructure is $1460 \mathrm{MPa}$ after 4-pass pressing, as compared to $403 \mathrm{MPa}$ of its coarsegrained counterpart, but with uniform elongation of merely $2 \%$. After annealing at $973 \mathrm{~K}$, the uniform elongation increases to $7 \%$ with the yield strength of $1100 \mathrm{MPa}$.

3. The various plastic responses and corresponding ability of strain hardening were analyzed in detail. The as-annealed microstructure indicates two transitions and three stages of strain hardening, which is associated with two possible mechanisms, i.e., the onset of yielding and deformation twinning in austenite, respectively. There is just one stage for deformed microstructure, which may be resulted from the formation of comparable strength between austenite and ferrite after 4-pass pressing. After annealing, however, a two-stage feature appears again, which may arise from the reintroduction of difference in yield strength between austenite and ferrite.

\section{Acknowledgements}

The financial supports by 973 Program of China (Nos. 2012CB932203, 2012CB937500 and 2010CB631004) and NSFC (Grants Nos. 11002151, 10721202 and 11072243) are gratefully acknowledged.

\section{References}

[1] K. Lu, L. Lu, S. Suresh, Science 324 (2009) 349-352.

[2] E. Ma, JOM 58 (2006) 49-53.

[3] C.C. Koch, Scr. Mater. 49 (2003) 657-662.

4] M.A. Meyers, A. Mishra, D.J. Benson, Prog. Mater. Sci. 51 (2006) 427-556

[5] Y.T. Zhu, T.G. Langdon, JOM 56 (2004) 58-63.

[6] Y.M. Wang, M.W. Chen, F.H. Zhou, E. Ma, Nature 419 (2002) 912-915.

[7] Y.H. Zhao, X.Z. Liao, S. Cheng, E. Ma, Y.T. Zhu, Adv. Mater. 18 (2006) 2280-2283.

[8] P.V. Liddicoat, X.Z. Liao, Y.H. Zhao, Y.T. Zhu, M.Y. Murashkin, E.J. Lavernia, R.Z. Valiev, S.P. Ringer, Nat. Commun. 1 (2010).

[9] X. Wu, N. Tao, Y. Hong, J. Lu, K. Lu, Scr. Mater. 52 (2005) 547-551.

[10] Y.O. Ma, J.E. Jin, Y.K. Lee, Scr. Mater. 52 (2005) 1311-1315.

[11] C.C. Koch, R.O. Scattergood, K.L. Murty, JOM 59 (2007) 66-70.

[12] S. Ankem, H. Margolin, C.A. Greene, B.W. Neuberger, P.G. Oberson, Prog. Mater. Sci. 51 (2006) 632-709.

[13] K.T. Park, S.Y. Han, B.D. Ahn, D.H. Shin, Y.K. Lee, K.K. Um, Scr. Mater. 51 (2004) 909-913.

[14] K.T. Park, S.Y. Han, D.H. Shin, Y.K. Lee, K.J. Lee, K.S. Lee, ISIJ Int. 44 (2004) 1057-1062.

[15] K.T. Park, Y.K. Lee, D.H. Shin, ISIJ Int. 45 (2005) 750-755

[16] J.J. Moverare, M. Oden, Metall. Mater. Trans. A 33 (2002) 57-71.

[17] J. Johansson, M. Oden, X.H. Zeng, Acta Mater. 47 (1999) 2669-2684.

[18] N. Jia, R.L. Peng, Y.D. Wang, G.C. Chai, S. Johansson, G. Wang, P.K. Liaw, Acta Mater. 54 (2006) 3907-3916.

[19] N. Jia, R.L. Peng, G.C. Chai, S. Johansson, Y.D. Wang, Mater. Sci. Eng. A 491 (2008) $425-433$.

[20] A. Belyakov, Y. Kimura, K. Tsuzaki, Acta Mater. 54 (2006) 2521-2532.

[21] R.Z. Valiev, R.K. Islamgaliev, I.V. Alexandrov, Prog. Mater. Sci. 45 (2000) 103-189.

[22] T.G. Langdon, M. Furukawa, M. Nemoto, Z. Horita, JOM 52 (2000) 30-33.

[23] Y. Iwahashi, Z. Horita, M. Nemoto, T.G. Langdon, Acta Mater. 46 (1998) 3317-3331.

[24] C.X. Huang, K. Wang, S.D. Wu, Z.F. Zhang, G.Y. Li, S. Li, Acta Mater. 54 (2006) 655-665

[25] T.A. Palmer, J.W. Elmer, S.S. Babu, Mater. Sci. Eng. A 374 (2004) 307-321.

[26] L.M. Wang, Z.B. Wang, K. Lu, Acta Mater. 59 (2011) 3710-3719.

[27] S.S. Hazra, E.V. Pereloma, A.A. Gazder, Acta Mater. 59 (2011) 4015-4029.

[28] N. Tsuji, S. Okuno, Y. Koizumi, Y. Minamino, Mater. Trans. 45 (2004) 2272-2281.

[29] C.X. Huang, G. Yang, Y.L. Gao, S.D. Wu, Z.F. Zhang, Mater. Sci. Eng. A 485 (2008) 643-650.

[30] M. Calcagnotto, Y. Adachi, D. Ponge, D. Raabe, Acta Mater. 59 (2011) 658-670.

[31] Y.I. Son, Y.K. Lee, K.T. Park, C.S. Lee, D.H. Shin, Acta Mater. 53 (2005) 3125-3134.

[32] S.S.M. Tavares, P.D. Pedroza, J.R. Teodosio, T. Gurova, Scr. Mater. 40 (1999) 887-892.

[33] H.W. Swift, J. Mech. Phys. Solids 1 (1952) 1-18.

[34] Y. Tomita, K. Okabayashi, Metall. Trans. A 16 (1985) 865-872.

[35] S.S.M. Tavares, M.R. da Silva, J.M. Pardal, H.F.G. Abreu, A.M. Gomes, J. Mater. Process. Technol. 180 (2006) 318-322.

[36] H.W. Zhang, Z.K. Hei, G. Liu, J. Lu, K. Lu, Acta Mater. 51 (2003) 1871-1881.

[37] B. Bay, N. Hansen, D.A. Hughes, D. Kuhlmann-wilsdorf, Acta Metall. Mater. 40 (1992) 205-219.

[38] D.H. Shin, I. Kim, J. Kim, K.T. Park, Acta Mater. 49 (2001) 1285-1292.

[39] X. Wu, N. Tao, Y. Hong, B. Xu, J. Lu, K. Lu, Acta Mater. 50 (2002) 2075-2084.

[40] B.Q. Han, E.J. Lavernia, F.A. Mohamed, Metall. Mater. Trans. A 35A (2004) 1343-1350.

[41] N.R. Tao, K. Lu, Scr. Mater. 60 (2009) 1039-1043.

[42] S. Vercammen, B. Blanpain, B.C. De Cooman, P. Wollants, Acta Mater. 52 (2004) $2005-2012$.

[43] Y.T. Zhu, X.Z. Liao, X.L. Wu, Prog. Mater. Sci. 57 (2012) 1-62. 